\title{
Research on Reform of Electronic Technology Experiment Teaching in Higher Vocational Colleges
}

\author{
CHEN Xuechang ${ }^{1, a}$ \\ ${ }^{1}$.Institute of Applied Electronics, Chongqing College of Electronic Engineering; Chongqing 401331, China \\ a.Email: pcboy2004@126.com
}

Keywords: Electronic Technology; Experimental Teaching; Teaching Reform

\begin{abstract}
Electronic technology experiment is a compulsory practical technical basic course of electronic information specialty in higher vocational colleges. It plays an important role in cultivating students' comprehensive quality and innovation ability. The teaching effect directly influences the training of follow-up courses and professional skills. However, there are some problems in the teaching of electronic technology in vocational colleges, which seriously affect the cultivation of students' practical ability. Deepening the reform of electronic technology experiment teaching is a very urgent need of higher vocational education. According to the requirements of higher vocational education talents training, the reform of electronic technology experiment teaching is explored, and the experimental teaching system suitable for the cultivation of oral standard of higher vocational education is established. Innovation experimental teaching content, explore new experimental teaching methods, update the experimental teaching methods, establish and improve the quality assurance of experimental teaching evaluation mechanism.
\end{abstract}

\section{Theoretical Introduction of Experimental Teaching}

Experimental teaching is the foundation of theoretical teaching. It is a bridge between the knowledge and practice. Only in practice can the innovation meet the demand of social productive forces. Electronic technology is a hands-on ability demanding professional, its practicality in the teaching of the course plays a vital role. One of the experimental teaching is the expansion of knowledge theory and supplement. Improvement of the practical ability of students is an important part of the experimental teaching.

The traditional experimental teaching equipment uses a plug-in platform, this experimental device has several shortcomings: firstly, the instrument variety and style is very small, the experimental device is too rigid, not only is not flexible and experimental teaching quality is not guaranteed. Secondly, many of the current teaching instruments are out of date, can't fully meet the needs of the market economy production target work, and related update is not timely. Thirdly, the equipment is not perfect, can't fully meet the experimental needs of the course. In view of these problems, this paper aims at the "electronic technology experiment" course to carry out some teaching reform, to achieve the current curriculum teaching to solve many problems ${ }^{[1]}$.

From the actual training, based on practical experience to improve the capacity of technology, teaching content under the electronic technology is only a deep understanding of the knowledge, but the level of vocational skills can't be greatly improved, the development of students with very serious constraints. Therefore, in the course of teaching reform, the college should integrate the practical operation concept into the teaching system, and create as many training opportunities as possible for the students, so that the students' vocational skills can be improved and improved in the practical training. From the perspective of career development, teaching content can expand and enhance students' understanding of electronic technology vocational skills, from a professional point of view to inspire students to enhance student interest in learning.

\section{Problem Analysis of Electronic Technology Experiment Course}

At present, the experiment course of electronic technology is only in the background of electronic technology. There are a lot of experiments in teaching, but there is a lack of exploration and innovation process in combination with other discipline or comprehensive ability. The selection of 
experimental materials is also a problem, teachers only explain the purpose and nature of the experiment, for its experimental principle, tell the process of experiment again, complete the experimental process, this traditional teaching model to enable students to master basic experimental skills, Innovation, students in a passive state, seriously restricting the students' subjective initiative ${ }^{[2]}$. Fig. 1 shows problems analysis of electronic technology experiment.

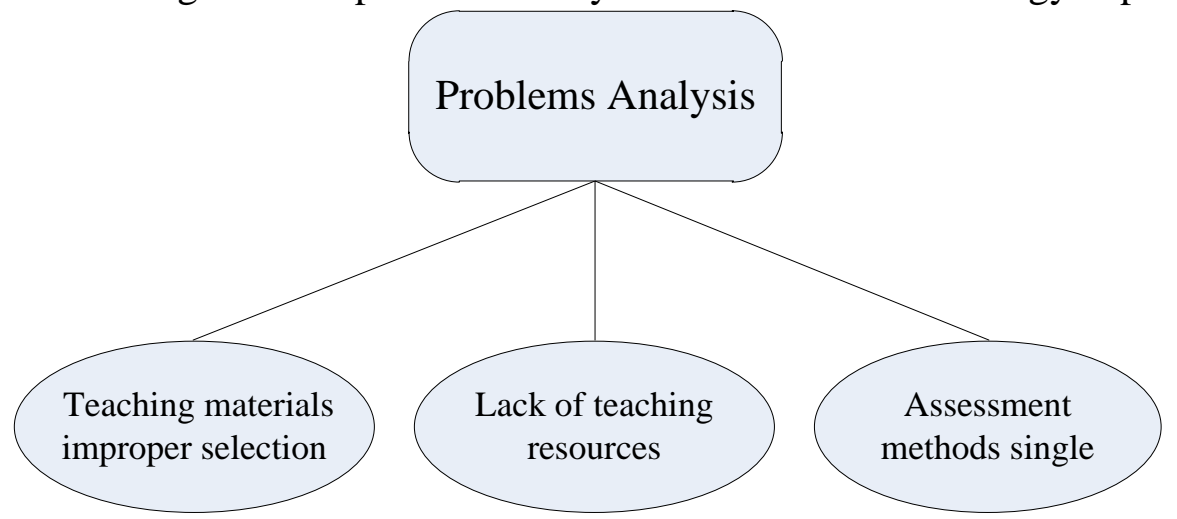

Fig. 1.The problems analysis of electronic technology experiment

As the current expansion of higher vocational colleges, electronic information technology, mechanical training tasks are also growing, the requirements of teaching resources, experimental machines are also more and more equipment in the process of overloading operation, which can't afford heavy teaching tasks. Experimental course assessment methods are also problems, the main assessment method is still based on experimental reports, and this experimental report is to copy the experimental steps to copy it again, and then fill in the experimental data, and most of these experiments are also very are false constructs. Such experimental reports can't be fully assessed curriculum, can't truly reflect the learning situation, and thus arouse the enthusiasm of the students in the experimental course, and it can't improve the students' hands-on practical ability.

The traditional experimental teaching mode can let the students master the basic experimental skills, but the students in the experimental teaching in a passive state, seriously restricting students' subjective initiative. The development of electronic technology is very rapid, and new theory, new pieces can't be applied in time in the electronic technology experiment teaching. Experimental teaching is an important part of professional teaching, and theoretical teaching complement each other, is an important means of training students practical ability. We should face up to the importance of experimental teaching for personnel training, and fully affirm the position of experimental teaching in the whole personnel training. We should face up to the importance of experimental teaching for personnel training, and fully affirm the position of experimental teaching in the whole personnel training. In view of these status quo, in order to strengthen education and training skills in two aspects of teaching guidance, and actively promote the teaching of electronic experimental technology reform, build a new curriculum conducive to student development ${ }^{[3]}$.

\section{Teaching Reform in Higher Vocational Colleges}

Vocational colleges in accordance with the core idea of curriculum reform: from the perspective of career development, teaching content to expand and enhance students' understanding of electronic technology vocational skills, from a professional point of view to inspire students to enhance student interest in learning. At the same time, the level of electronic technology curriculum content is divided, in accordance with professional basic skills, professional core skills, common skills standards highlight the focus of electronic technology, step by step, enhance the teaching of electronic technology skills. Fig.2 shows teaching reform measures in higher vocational colleges. 


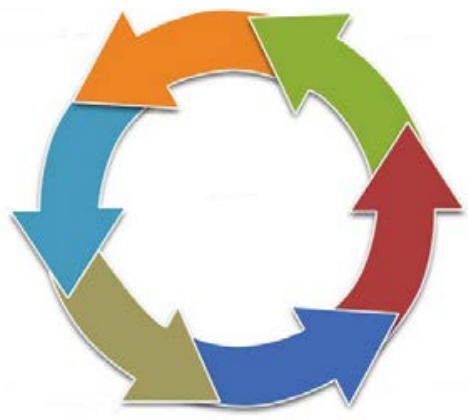

Fig. 2.Teaching reform measures in higher vocational colleges

In the process of reform, higher vocational colleges can choose the teaching methods reasonably from the above contents, and fully mobilize the students' subjective initiative and improve the students' learning efficiency, which has a very good promotion effect on students' professional electronic skills. The current teaching process, teachers can use the following teaching techniques to create a good learning atmosphere. In the process of implementing the teaching method, teachers should regard the students as the main body of the electronic technology course, make clear their own guiding significance, take the students 'electronic vocational skills training as the reference point, and make the students' guide students to actively into the classroom. Vocational colleges in the course of setting up electronic technology courses practice from the student career development direction to career development as the main content, make full use of school resources and social resources for students to create a good training platform.

The vocational training colleges should take the reform as the center and make clear the comprehensive training level. The teaching and training should be based on the professional needs, set up the vocational training system on the basis of the vocational skills and the knowledge of the electronic technology curriculum. In the course of reforming the evaluation system, higher vocational colleges should abandon the evaluation methods which rely on the test results and training results in the traditional teaching, transfer the evaluation focus from the result to the process, pay attention to the knowledge, the evaluation of the ability, the effectiveness of electronic technology curriculum evaluation, scientific and rational. According to the above-mentioned needs of professional development, the weights of these indicators should be clearly defined, and the scores of each part should be weighted according to the weight indicators, so as to form a high-quality assessment system ${ }^{[4]}$.

\section{Improve New Experimental System of Electronic Technology Course}

In accordance with the overall teaching and student knowledge and ability to the extent of the application of electronic technology courses of the experimental class is divided into three levels. Arrangement of a simple basic content of the experiment, so that students in the experimental process to understand the content of the experiment, learning a variety of instrumentation operation, learning experimental data measurement and processing methods to develop serious work attitude. The ability to use the knowledge of students under the guidance of teachers in the analysis of a given function, characteristics, and according to the circuit or system functions under the guidance of teachers to design the circuit or system to achieve this function, the final experimental test. Through the training of students in the case of flexible use of knowledge to improve the design capacity of the application of electronic technology professional practice teaching system is divided into three levels of experiment and two independent teaching practice teaching platforms.

Construction of electronic design training base within the school, students practice and innovation. Through the construction of the base, cultivate professional ability strong student backbone, and through their demonstration and leading role, and gradually form a good professional learning atmosphere, to play its professional orientation role. Outside the practice base, highlighting the interactive teaching and learning outside the school. In order to make the practice outside the school to implement, so that students understand the actual engineering design requirements, 
improve the ability of students to adapt to work, and enterprises should strengthen links in personnel training, technical services, personnel training and many other internship with the establishment from both sides reciprocity ${ }^{[5]}$.

Laboratory construction side, the purchase of new experimental apparatus and equipment, which all the updated electronic, electrical laboratory equipment and equipment, the new electronic training laboratory, single-chip microcomputer laboratory and electronic integrated laboratory. In addition, we should pay close attention to the daily management of the laboratory, require equipment to improve the rate and experimental use rate. The teaching and research section of each semester to develop work plans, in the course of practice teaching, organization of teachers lectures, assessment, discussion, help teachers develop practical curriculum teaching plan, regular classes, exchange of learning experiences, listen to students on the practice of teaching the views and suggestions on the student's response to rapid response, timely notification for the teachers to implement the rectification, and strive to improve the quality of teaching.

\section{Conclusions}

Electronic technology experiment is an important course of electrical and electronic specialty in higher vocational colleges, and also an important link for students to acquire professional skills and to improve the ability of problem analysis and problem solving. This paper analyzes the problems existing in the experimental teaching in the course of traditional professional electronic teaching, and expounds some reform measures for these problems. Practice proves that these reform measures have good effect on cultivating highly skilled electronic talents. In short, the reform of experimental teaching, should be from the establishment of experimental teaching system, experimental teaching innovation content, explore new experimental methods, update the experimental teaching methods, improve the experimental assessment mechanism and so on to explore and effectively develop and train to meet the needs of society higher technology applied talents.

\section{References}

[1] LIU De-jin. Elective and electronic experimental teaching reform thinking [J]. Gansu Science and Technology, 2006 (3): 154.

[2] Hu Shujun, Reform Electronic Experiment is foster innovation [J]. Huanggang Vocational and Technical College, 2009 (1): 83-85.

[3] W. G. Beazley, vocational mechanism professional "Metalworking Training" Teaching Reform Course Day items [J]. Wenzhou Vocational and Technical College, 2010 (3), 86-88.

[4] Su Zhihong Project Approach Teaching in electricity technical courses [J], Chinese Science and Technology Information, 2011 (2): 189-190.

[5] YANG Huimin. Exploration and Reform of Electronic Technology Curriculum Practice [J] .Labor Research and Exploration, 2013 (3): 61-63. 